\title{
LITIGATION AND THE COMPLEXITIES OF SINKHOLE INSURANCE CLAIMS IN FLORIDA
}

\author{
Larry D. Madrid
}

PE, D.GE, F.ASCE, President, Madrid Engineering Group, Inc., Bartow Florida

\begin{abstract}
The entirety of peninsular Florida is underlain by relatively young limestone bedrock and overlain by sands that easily ravel into voids and cavities within the limestone. Surficial expressions of karstic activity are immediately evident in its thousands of circular lakes, wetlands, and cypress heads. Additionally, Florida has had literally tens of thousands of subsidence-related insurance claims over the past two decades, far surpassing the entire history of property insurance before that. The peak came around 2011, the year that new legislation made it much harder for a homeowner to prove a claim. The issue was essentially 'what is the definition of structural damage?' as defined by Florida Statute related to property insurance and specifically sinkhole coverage. Prior to 2011, a clear definition of structural damage did not exist, consequently the attorneys maintained that the plain definition (structural damage is damage to a structure) held, in spite of many geotechnical and structural reports that defined structural damage as an engineer would deem - loss of load carrying capacity. Consequently, cosmetic damage that was not remotely "structural" was considered damage by the courts, and legal cases blossomed out of control.
\end{abstract}

In 2011, Florida Statutes redefined "structural damage" using five separate criteria. These criteria include, for example "interior floor displacement or deflection in excess of acceptable variances as defined in ACI $117-90$ or the Florida Building Code, which results in settlement-related damage to the interior such that the interior building structure or members become unfit for service or represents a safety hazard as defined within the Florida Building Code...". Other criteria have to do with foundation displacement; leaning or listing of the building; or ground movement that results in portions or all of the building likely to imminently collapse. Of course, there are additional criteria and exceptions. Overall, these statutory changes have resulted in significantly fewer sinkhole claims, in spite of the occasional sinkhole that enraptures the news media (for example, the March 2013 death of Mr. Jeffrey Bush as a result of sinkhole collapse below his bedroom). So while all property insurance companies in Florida still cover "catastrophic ground cover collapse" for all homes, there are far fewer of these claims to deal with as the law has become more sophisticated.

\section{Introduction}

Florida property insurance is more dynamic than most markets. Most property insurance claims are about fire or water damage, but Florida's property insurance also has to cover hurricanes, which provide significant damage and repair costs. Additionally, a large portion of Florida is underlain by limestone that is relatively near the surface (with 30 meters) and subject to karst activity. The proximity to the surface, the relative thickness of sand versus clay overlying the limestone, the downward gradient of surface waters to the aquifer, and the propensity for dissolution increases sinkhole occurrence.

Because of this sinkhole activity, land improvements such as homes and other buildings located in karst regions had been damaged such that sinkhole insurance was added to the list of perils that were required to be covered by property insurance, under Florida law. The author is unsure when the property insurance requirement was initiated, but it was decades ago. Initially, there was no distinction among various types of damage, and prior to 2007 all sinkhole insurance was comprehensive. In 2004, a "Sinkhole Summit" occurred among the geologist community to convene experts in the field of Florida geology. Of the 26 participants, 13 were $\mathrm{PhD}$ geologists. The result of this meeting was the 2005 Special Publication 57 from the Florida Geological Survey, in which a consistent and rather comprehensive methodology was set forth to investigate sinkhole insurance claims - this included SPT borings, hand auger borings, test pits to expose the foundation, GPR and electrical resistivity surveys, as well as floor elevation surveys and photodocumentation. These were generally incorporated into changes to the Florida Statutes in 2007 regarding sinkhole insurance. Regulations were again clarified in 2011 to present day law. Here are some of the main parts of the law:

The current mandate for property insurance companies is the following:

"Every insurer authorized to transact property insurance in this state must provide coverage for a catastrophic ground cover collapse." (CGCC) 
In other words, all properties are insured for catastrophic sinkholes that are further defined below:

(a) "Catastrophic ground cover collapse" means geological activity that results in all the following:

1. The abrupt collapse of the ground cover;

2. A depression in the ground cover clearly visible to the naked eye;

3. Structural damage to the covered building, including the foundation; and

4. The insured structure being condemned and ordered to be vacated by the governmental agency authorized by law to issue such an order for that structure.

The conditions above must all be met, meaning that it is indeed a rare situation that would develop for these conditions. Most sinkhole activity in Florida is not sudden collapse sinkholes, but rather dissolution type sinkholes that are slower, occurring over days, weeks, and years and causing settlement damage that is small at first, but then progresses over time. This type of sinkhole activity can be covered, but is a rider on the insurance policy rather than part of the insurance coverage as it was in the past.

A further detail that is required is to define item 3 above, "structural damage". Prior to 2011, this term was not further defined in the insurance regulations related to sinkhole coverage, Florida Statutes Chapter 627.706. Without a legal definition, attorneys argued that "structural damage" was plainly defined as "damage to a structure", which is a very for a very broad definition that covers not only a) what a structural engineer would say was 'structural damage' but also b) cosmetic damage, which by definition is superficial and would not result in loss of load bearing capacity of structural elements.

\section{The Five-Fold Test of Structrual Damage}

In 2011, these five tests for structural damage were added to the language as clarifications of the previous statutes.

"Structural damage" means a covered building, regardless of the date of its construction, has experienced the following:

1. Interior floor displacement or deflection in excess of acceptable variances as defined in ACI $117-90$ or the Florida Building Code, which results in settlement-related damage to the interior such that the interior building structure or members become unfit for service or represents a safety hazard as defined within the Florida Building Code;
2. Foundation displacement or deflection in excess of acceptable variances as defined in ACI 318-95 or the Florida Building Code, which results in settlement-related damage to the primary structural members or primary structural systems that prevents those members or systems from supporting the loads and forces they were designed to support to the extent that stresses in those primary structural members or primary structural systems exceeds one and one-third the nominal strength allowed under the Florida Building Code for new buildings of similar structure, purpose, or location;

3. Damage that results in listing, leaning, or buckling of the exterior load-bearing walls or other vertical primary structural members to such an extent that a plumb line passing through the center of gravity does not fall inside the middle one-third of the base as defined within the Florida Building Code;

4. Damage that results in the building, or any portion of the building containing primary structural members or primary structural systems, being significantly likely to imminently collapse because of the movement or instability of the ground within the influence zone of the supporting ground within the sheer plane necessary for the purpose of supporting such building as defined within the Florida Building Code; or

5. Damage occurring on or after October 15,2005 , that qualifies as "substantial structural damage" as defined in the Florida Building Code.

The first four of these five definitions follow a logical course of progressively worsening conditions. When movement occurs in a building, it is fairly easy to have interior floor displacements; it takes a little more settlement to cause concentrated loads such that the primary structural load bearing elements exceed their design by $33 \%$, and even more settlement to cause tilting in the walls sufficient that there is eccentric loading outside the 'kernel' or middle third of the base. The fourth definition is the longest and most difficult to properly 'unpack'; but it basically says the building is in an imminent collapse mode. Naturally, geologists and engineers initially read this as the 'collapse' referred to the soil or rock beneath the structure, and not the structure itself. The fifth definition refers more to the timing of the damage, disqualifying damages prior to 2005 , with "substantial structural damage" defined as a $20 \%$ or greater loss load carrying capacity.

The bottom line of the changes in regulations is that there must now be "structural damage" (as defined above) present that may be the result of sinkhole 
activity. Structural Damage Assessments are completed with limited or no geotechnical evaluation first, and if there is sufficient structural damage present, a sinkhole investigation may proceed to determine if sinkhole activity is a cause of the damage. With these regulatory changes, a significant reduction in sinkhole claims has occurred, based on the number of sinkhole assignments our company (and many sinkhole experts) have received since 2012. Other recent and significant industry changes include the following:

\section{The Managed Repair Progam}

Citizens Property Insurance Corporation, the largest residential property insurer in Florida, is a not-for-profit, tax exempt government entity created in 2002 to be an insurer 'of last resort' for high risk policies, such as hurricane prone areas and sinkhole prone areas of Florida. In response to rising numbers of sinkhole claims and in some cases fraud by contractors, Citizens created the Managed Repair Program which did two things to bring things under control: created a pre-approved Contractor Network of licensed and vetted specialty contractors to do sinkhole repair (grouting and underpinning of structures); providing multiple quotes for repairs to the homeowner; provided third-party monitoring services to assure the contractor's performance and conformance to the specifications; and provide a 3-year warranty to the homeowner. This program has significantly reduced the number of "fly-by-night", unqualified contractors from doing substandard repairs to homes.

\section{The Neutral Evaluation Process}

In the event that the homeowner disagreed with the engineer's determination of whether or not sinkhole activity was a cause of damage, or disagreed with the engineer on the repair program for the structure, a Neutral Evaluation program was established by the Office of Insurance Regulation. A Neutral Evaluator or N.E. (who was either a geotechnical engineer, a structural engineer or a professional geologist) was assigned to the case to provide a third-party opinion to help resolve the dispute. The NE determines for themselves a cause of loss by reviewing all previously completed investigations from the site and if necessary conducting his/her own investigation including additional testing. Neutral Evaluation is mandatory if requested by either the insured or the insurer, and must be allowed reasonable access to the interior and exterior of the property. The evaluation is non-binding, but the NE may be brought into the courts in case the claim cannot be settled after the Evaluation.

\section{Litigation}

As with most property insurance claims that are disputed using the legal system in the US, most are settled out of court. However, there are many sinkhole claims still in the court system, and some still outstanding from before the rule change of 2011. The insured homeowner's attorney hires an engineer who says that the damage is related to sinkhole activity, and the insurance company has their own expert who says the damage is due to other causes. These cases are most often settled by jury decisions, and all things being equal, appear to strongly favor homeowners over insurance companies. Further, instead of being solved by science and fact, court cases are often solved on emotions or less than full understanding of the scientific issues. 
